\title{
Das Unheimliche como clave hermenéutica en los relatos de M. L. Kaschnitz
}

\author{
Santiago MARTíN ARNEDO \\ Universidad de Granada \\ santiagoma@correo.ugr.es
}

Recibido: 18 de noviembre de 2013

Aceptado: 22 de enero de 2014

\section{RESUMEN}

Marie Luise Kaschnitz introduce en sus relatos das Unheimliche como elemento esencial a partir del cual los personajes sufren una transformación: amplían su autoconciencia (Bewusstsein) que se convierte en conciencia moral (Gewissen). Lo inquietante contiene elementos sobrenaturales o mágicos y resulta turbador en cuanto la normalidad se convierte en algo extraño. Los orígenes de este concepto han sido estudiados por M. Heidegger (angustia radical), E. Jentsch (inseguridad intelectual para distinguir lo animado de lo inanimado) y S. Freud (represión de un conflicto interior).

Palabras clave: Unheimlich, Heidegger, Freud, Kaschnitz.

\section{Das Unheimliche as an Hermeneutical Key in the Short Stories of M. L. Kaschnitz}

\begin{abstract}
Marie Luise Kaschnitz introduces in her short stories das Unheimliche as an essential element, from which the characters undergo a transformation: it expands their self-awareness (Bewusstsein) that becomes moral conscience (Gewissen). The "uncanny" contains supernatural or magical elements. This is disturbing as soon as normality becomes something strange. The origins of this concept have been studied by Heidegger (radical anguish), Jentsch (intellectual insecurity to distinguish the animate from the inanimate) and Freud (suppression of an internal conflict).
\end{abstract}

Keywords: Unheimlich, Heidegger, Freud, Kaschnitz.

SUMARIO: 1. Introducción. 2. Definición previa de lo "inquietante". 2.1. Definición ontológica. 2.2. Definición psicológica. 3. Los relatos de Kaschnitz como ejemplo de lo "inquietante". 3.1. Análisis del relato Eines Mittags, Mitte Juni. 3.2. Análisis del relato Das dicke Kind. 4. Conclusiones.

\section{Introducción}

Das Unheimliche es un concepto de historia muy densa, pero este estudio va a partir de y ceñirse a la definición que Martin Heidegger (1977) y Sigmund Freud (1919) hicieron de él, para utilizarlo como herramienta de análisis literario en el caso de los relatos de Marie Luise Kaschnitz (1901-1974). Esta autora es muy prestigiosa en Alemania, y sin embargo relativamente desconocida allende sus fronteras. Reconocida poetisa, autobiógrafa y autora de Hörspiele, sus relatos han 
despertado un creciente interés a partir de 1950. En ellos se exponen conflictos personales, siempre con un trasfondo de alto contenido biográfico, junto a elementos irracionales, mágicos e inexplicables ${ }^{1}$. No son relatos fantásticos, en cuanto su objetivo no es explorar el mundo de lo sobrenatural. De hecho, el lector no tiene claro hasta qué punto ha sido todo producto de un sueño o del delirio de la (casi siempre) protagonista. De ahí que formalmente estén construidos utilizando numerosas alusiones y elusiones. Lo que interesa a la escritora es hacer presente las zonas oscuras e irracionales que laten en el fondo de sus personajes y el modo en que éstos se enfrentan a la angustia. Ha sido Tania Oldenhage (2002: 21) quien ha llamado la atención sobre la relación entre Freud y Kaschnitz, en el sentido de que algo que tenía que estar oculto (reprimido) aflora a la superficie. Esta técnica narrativa alemana de posguerra (Doderer 1977: 40) se ha relacionado asimismo con la irrupción de las circunstancias más trágicas dentro de la normalidad durante la guerra, como es el bombardeo o la presencia de cadáveres en las calles. Pero esta irrupción de lo extraño (Mikyung 2003: 37 y ss.) está al servicio del propio viaje interno de descubrimiento, como afirman Bachmann/Schweikert: "Die Figuren begegnen Spiegelungen des eigenen Ichs, ohne dass sie dessen sofort wahr werden" (en Kaschnitz 2002: 206). Todo es un proceso de conocimiento, que acaba siendo conocimiento moral; gracias a que se produce un extrañamiento, lo incuestionado deja de ser tal y la profundidad del conocimiento se amplía.

\section{Definición previa de lo "inquietante"}

Por un lado, Heidegger concibe lo unheimlich como una forma en la que el Dasein accede a su propia autenticidad. Para él, esta inquietud es un tipo de angustia definida por la pérdida del suelo patrio en amplio sentido, que priva de la confortable sensación de "estar en casa", de la convicción de que ya no hay peligro. Y sin embargo, este via crucis simboliza la madurez del juicio del Dasein, que le hace llevar una existencia trágica en tanto le hace "caer" (según terminología de Heidegger) de las opiniones impersonales y le abre al mundo en soledad radical. Asimismo le lleva a enfrentarse al abismo ontológico que impide al hombre auto-fundamentarse en sí mismo. Por otro lado, Freud define el concepto desde el paradigma psicoanalítico. Se puede afirmar que desde su teoría este concepto se torna muy fructífero, sin que por ello exista la necesidad de hacerse cargo de todas las consecuencias que él extrae, como se verá más adelante. El concepto hermenéutico que se propone recoge de Heidegger la idea de que lo unheimlich convierte en extraño aquello que tanto tiempo ha sido familiar e incuestionado. Y con Freud se añadirá otra connotación a este término: aquello que debiendo permanecer oculto, sale a la luz. Freud recalca el matiz de inmadurez de la Unheimlichkeit, en cuanto se extrapola el carácter animista a un entorno, que se con-

${ }^{1}$ Aparte de los dos relatos aquí analizados, la irrupción de lo sobrenatural es casi generalizada en los relatos de Kaschnitz: Der Bergrutsch (1952), Der Thunsch (1966), Eisbären (1966), Jennifers Träume (1960), Gespenster (1960), Das Wunder (1960), Schiffgeschichte (1960), etc. 
vierte en fuente de temores y miedos, como si todavía viviéramos en el mundo encantado "pre-weberiano" ${ }^{2}$. De igual modo que el niño es incapaz de diferenciar su yo del exterior y de los otros-yo en sus primeras etapas de desarrollo, según habían descrito Piaget y Kohlberg ${ }^{3}$, lo misterioso aparece cuando a las casualidades se les atribuye un significado oculto, cuando a los objetos inanimados se les dota de animación, etc.

\subsection{Definición ontológica}

Heidegger introduce el análisis del concepto das Unheimliche en el parágrafo 40 de Sein und Zeit (1977: 244-253), en el camino de su exégesis del Dasein y de los existenciarios, es decir, de aquellas características que lo definen, no eventualmente, sino ontológicamente. Por ejemplo el "comprender-(se)" no es un estado que pueda activarse o inactivarse contingentemente, sino que, como afirma Heidegger "im Verstehen liegt existenzial die Seinsart des Daseins als Seinkönnen" (1977: 143). Heidegger se mueve, o esa es su intención, en un plano trascendental y no psicológico.

Heidegger comienza de entrada distinguiendo entre Angst (que se ha traducido tradicionalmente como "angustia") y Furcht (traducida por "temor"). Él acepta que las relaciones fenomenológicas (es decir, desde el método de análisis que él utiliza) aún son oscuras. Heidegger ha definido la causa del temor de la siguiente manera: "das Wovor der Furcht ist je ein innerweltliches, aus bestimmter Gegend, in der Nähe sich näherndes, abträgliches Seiendes, das ausbleiben kann" (1977: 246). Conviene reparar en que lo que causa el miedo es algo mundano, que aparece en el mundo o es una parte de él, y que por alguna razón se considera nocivo. Además, proviene de un lugar determinado, no es un temor sin objeto, es algo que amenaza, en el sentido de que puede acercarse, pero podría no hacerlo. En español se dice "tengo miedo" y "me da miedo", donde sutilmente se refleja esta distinción, como amenaza localizada.

Muy al contrario, la angustia no sabe señalar ni en el tiempo ni en el espacio la causa de donde proviene la amenaza. Es como si no estuviera en un lugar definido, o al menos al alcance del conocimiento, "sieht die Angst auch nicht ein bestimm-

\footnotetext{
${ }^{2}$ Weber caracteriza el proceso de racionalización de tal forma "daß es (also) prinzipiell keine geheimnisvollen unberechenbaren Mächte gebe, die da hineinspielen, daß man vielmehr alle Dinge im Prinzip - durch Berechnen beherrschen könne. Das aber bedeutet: die Entzauberung der Welt. Nicht mehr, wie der Wilde, für den es solche Mächte gab, muss man zu magischen Mitteln greifen, um die Geister zu beherrschen oder zu erbitten. Sondern technische Mittel und Berechnung leisten das. Dies vor allem bedeutet die Intellektualisierung als solche" (WeBER 1985: 593).

${ }^{3}$ La tesis la he tomado de J. Habermas. Al explicar éste a Piaget y Kohlberg, insiste en que se pasa de una etapa de madurez cognitiva a la siguiente no por almacenar nuevos contenidos, sino por ser capaz de aplicar nuevas categorías a la realidad: "Neben die objektive Welt existierender Sachverhalte tritt die soziale Welt, der Aktor als rollenspielendes Subjekt ebenso angehört wie weitere Aktoren" (HABERMAS 1981: 132).

${ }^{4}$ De hecho en el diccionario DUDEN (2012), Angst se relaciona etimológicamente con "angustia", en el sentido de Enge, Beklemmung (2012: 38), cuando se siente estrechez, que no hay escapatoria. En el actual alemán significa sin más el miedo en su sentido más natural, como el temor a un peligro inminente. Por tanto la distinción de Heidegger es pertinente sobre todo en su contexto hermenéutico.
} 
tes 'Hier' und 'Dort', aus dem her sich das Bedrohliche nähert" (1977: 248). Pero que el lugar de origen no pueda ser especificado, no significa que no exista. De hecho, paradójicamente, está ahí, sentimos su cercanía, porque nos ahoga, nos corta el aliento; y al mismo tiempo no está en ningún lugar; "es ist schon da [...] und doch nirgends" (1977: 248). La angustia no se enfrenta a algo que sea parte del mundo, no está dentro de él. No es un objeto identificable como nocivo. Será la misma mundanidad, concluirá Heidegger, la causa de la angustia. Por ello, afirma Heidegger con rotundidad "Die Welt hat den Charakter völliger Unbedeutsamkeit" (1977: 247). Y si el mundo no es significativo para crear el peligro, tampoco lo es para salvarlo ${ }^{5}$. No tiene significado o relevancia, porque lo que causa la angustia es precisamente, no que el mundo sea así o de otra manera, sino el mismo hecho de estar en el mundo, el ser mundano: es pura indeterminación, pues no se encuentra por ninguna parte $^{6}$. Y precisamente porque no podemos señalar esta $o$ aquella parte del mundo como razón de nuestra angustia, ni siquiera la suma de todas las partes, es por lo que la mirada se vuelve a la mundanidad en general, diríamos, a la forma y no al contenido, es el mundo como concepto formal lo que está en cuestión y su misma existencia.

Pero el estado de angustia es la forma en que el Dasein se abre al mundo. Por eso entraña tanto potencial explicativo. El resultado es emotivamente desesperanzador: "die Welt vermag nichts mehr zu bieten, ebensowenig das Mitdasein Anderer" (1977: 249). Ni siquiera la compañía del otro consuela. Gracias a esta "caída", a este regreso al fondo abisal del que sabe que no se sostiene a sí mismo y que se descubre indigente de fundamento, el Dasein se individualiza y se vuelve auténtico en tanto que no es arrastrado por las opiniones mayoritarias o anónimas y cobra conciencia de su singularidad, y vuelve su mirada extraviada a su mismo ser. Como si desde la radical soledad inaugurara la olvidada pregunta por el ser. El precio que hay que pagar a cambio es, por un lado, el de la insolidaridad, entendida como la incapacidad de hacer mío el sentimiento del otro, y, por otro lado, el del desprecio del lenguaje como vehículo social del pensamiento, pues el lenguaje es una creación de la comunidad que siempre y de antemano excluye todo solipsismo ${ }^{7}$.

Así pues, cuando se siente lo "inquietante" como forma de angustia, se tiene la sensación de no sentirse ya como en casa. Esa es la característica esencial, no estar

\footnotetext{
${ }^{5}$ En una entrevista concedida a Frederick de TOwARNICKI (1969) traía Heidegger a colación la famosa cita de Hölderlin "Wo aber Gefahr ist, wächst Das Rettende auch". A Hölderlin por cierto, en esta misma entrevista, lo llama "der Vor-gänger der Dichter in dürftiger Zeit".

${ }^{6}$ En este preciso sentido afirmaba WITTGENSTEIN: "wir fühlen, dass selbst, wenn alle möglichen wissenschaftlichen Fragen beantwortet sind, unsere Lebensprobleme noch gar nicht berüht sind" (1973: 180), porque el problema no es cómo el mundo sea, sino el que sea, situándose de este modo Wittgenstein en una perspectiva metafísica muy afín a la heideggeriana.

7 APEL (1976) opone el "apriori del lenguaje" al "apriori de la conciencia" en su crítica a las filosofías de la conciencia. El lenguaje, por su propia naturaleza, sitúa al hablante más allá del solipsismo de la conciencia, que es siempre ya social. Como veremos, Kaschnitz rompe el círculo del solipsismo a través de la "com-pasión". Para ella, "el otro" será el camino para superar la angustia del desarraigo, será la forma de fracturar la soledad radical. El lenguaje literario por su parte será el medio, la terapia que nos vuelve a ligar al exterior.
} 
en casa; de ahí la raíz heim en la palabra alemana. La "casa" es el conjunto de convicciones incuestionadas a través de las cuales (gracias a la regularidad, por ejemplo) el sujeto se hace una imagen estable de su circunstancia, es el "suelo", literalmente, es el entorno que se controla y sobre el que se apoya, su terruño. Nada ofrece una confianza tan espontánea y agradable como la protección del hogar. Cuando el legado interpretado de la tradición, cuando las certezas que se comparten incuestionadamente se vienen literalmente abajo, aparece el vértigo que lo aísla, porque se siente desarraigado. Aunque esta expulsión de la "alltägliche Öffentlichkeit des Man" (1977: 251), donde el man es lo impersonal (lo que todos sostienen, sin sostenerlo propiamente nadie, el "se" dice, "se" hace, etc.), supone una asunción de la propia individualidad, y es entonces cuando tenemos que posicionarnos ante el hecho del mundo, sin recurrir a tópicos comunes. Y precisamente esta falta de referencias es lo que produce la angustia. Angustia y autenticidad son dos caras de la misma moneda. Este estado de autenticidad es singularmente anómalo, y lo es, porque el Dasein para sí mismo puede quedar oculto "durch die öffentliche Ausgelegtheit des Man in seiner Eigentlichkeit" (1977: 251), y de hecho, este quedar oculto para sí mismo es lo que habitualmente ocurre.

Heidegger insiste en presentar ontológicamente un concepto sin la precariedad metodológica y azarosa de una psicología en ciernes ${ }^{8}$. Lo que podría ser una indefensión aprendida, aquí es un rasgo de autenticidad existencial, por el que uno se abre al mundo y al 'saber-se' "estando en el mundo", según se expresa Heidegger. Es muy importante no "con-fundir" estos dos niveles de análisis: pues el miedo por causas psicológicas "wird nur möglich, weil das Dasein im Grunde seines Seins sich ängstet" (1977: 252), lo cual, es un postulado de profundas consecuencias.

\subsection{Definición psicológica}

Freud se ocupa de este concepto en un texto (1966: vol. 12, 229-268) que publicó en 1919. Allí relaciona el método psicológico con la teoría literaria. Él mismo había sentido la vocación de ser escritor y recurre con frecuencia a los ejemplos de la literatura. La relación del psicoanálisis con la literatura desde entonces ha sido de hecho casi simbiótica? .

Das Unheimliche ha sido tradicionalmente relegado a juicio de Freud por la estética, menos preocupada de teorizar sobre lo desagradable que sobre lo agradable. De

\footnotetext{
${ }^{8}$ HeIDEGGER admite a vuela pluma (1977: 252) que el estado de angustia puede ser inducido por desórdenes físiológicos. Afirma incluso que en este caso, para que dichos desórdenes desemboquen en angustia, previamente ha de estar configurada esa posibilidad en el Dasein. Elude el aspecto altamente problemático sobre el origen de nuestros estados emocionales, y por ende la posible pertinencia de las diferentes terapias: la palabra o la pastilla. Hay que tener en cuenta que para él la relación básica del Dasein con su mundo es un encontrarse afectivo, no un acto de intelección. Lo inhóspito se siente más que entenderse. De esta forma soslaya el tema sobre la prioridad del desencadenante de los afectos: ¿una idea nos induce la angustia, o el desorden de nuestro cuerpo suscita ideas negativas en nosotros?

${ }^{9}$ Pouh (1997), RATtNer/Dantzer (2010) y VOn Matt (2001).
} 
hecho, "lo inquietante" ha sido históricamente tematizado por muy pocas disciplinas, y la excepción a este panorama es, en su opinión, el estudio de E. Jentsch (1906: 195-198), de carácter psiquiátrico, que es a su vez el punto de arranque y de apoyo de Freud. Das Unheimliche, asegura Freud, se relaciona primariamente con aquello que nos produce miedo, temor. Pero son tantos los matices y las connotaciones que moldean esta palabra, que lo que él se propone es dar al menos con el núcleo común que compartan todos los usos de esa palabra. La primera y no menor dificultad en el estudio de das Unheimliche es "dass die Empfindlichkeit für diese Gefühlsqualität bei verschiedenen Menschen so sehr verschieden angetroffen wird" (1966: 230). Las sensaciones han pertenecido históricamente al reino de la subjetividad, y es muy difícil cuantificarlas y cotejarlas. Freud, muy cauto metodológicamente, espera al menos que las conclusiones a las que llegue merezcan el asentimiento de la mayoría, pues en el terreno de la interpretación no existen cadenas de razonamientos unívocos y cerrados, que provoquen un acuerdo espontáneo y universal.

Freud propone dos estrategias para inquirir el significado de das Unheimliche, que acaban convergiendo en un mismo resultado: estudiar la etimología de la palabra y sus diferentes usos lingüísticos y estudiar qué estímulos desencadenan en las personas esa sensación. Freud muestra al principio la conclusión a la que luego llegará definiendo lo inquietante como "jene Art des Schreckhaften, welche auf das Altbekannte, Längstvertraute zurückgeht" (1966: 231). Así pues se trata de un tipo de temor, algo que produce susto o al menos inquietud, y que remite a un contexto en el que todo era hasta entonces familiar, conocido desde antiguo o que nos generaba una confianza incuestionada. Y ocurre que "este incuestionado" de pronto se nos vuelve ajeno, y el no saber a qué atenernos nos causa miedo. Y este es el esquema profundo del que se nutren muchos de los relatos de Kaschnitz, casi literalmente. Como si Kaschnitz, aunque no es cierto ${ }^{10}$, hubiese estudiado a Freud para seguirlo fielmente. Kaschnitz utiliza el calificativo "inquietante" frecuentemente en sus relatos, para describir personas o lugares, y llega a intitular incluso una publicación de relatos como Unheimliche Geschichten (Kaschnitz 1969). Y la pregunta es ¿cómo es posible que lo familiar se nos vuelva extraño? ¿Extraño en qué sentido?

Por el camino de la exégesis filológica, Freud analiza pormenorizadamente el significado de la palabra en diferentes idiomas y su empleo diacrónico en la lengua alemana. Por un lado, es obvio que das Unheimliche se opone a heimlich, heimisch, lo que pertenece a la casa, lo familiar, allí donde me siento a salvo de los peligros, en "behaglicher Ruhe" (1966: 233), incluso en cierto estado de alegría, de serenidad. Por negación, das Unheimliche sería lo desconocido y lo que provoca desconfianza. Ahora bien, si todo lo unheimlich es desconocido, no todo lo desconocido es unheimlich. Algún resorte debe operar en lo desconocido para que éste se convierta en das Unheimliche. Por otro lado, existe otra vertiente significativa muy potente, en la que heimlich significa lo que está oculto, escondido, aque-

10 “[...] auch hatte ich damals keinerlei nähere Kenntnisse der Psychoanalyse" (KASCHNITZ 1982: vol. 7, 972). 
llo a lo que los demás no deben tener acceso. Por ejemplo, Freud cita al escritor romántico Adelbert von Chamisso (1781-1838), quien habla de "die heimliche Kunst der Zauberei" (1966: 234), amén de otros muchos ejemplos que utiliza Freud para justificar la connotación de la palabra como algo que encierra un secreto velado a la vista de los demás. Sorprendentemente, das Unheimliche se presenta como el antónimo de heimlich (en el sentido de familiar y que suscita confianza), pero no de su otra acepción como "escondido" y "oculto", es decir, das Unheimliche no significa lo que se muestra. Profundizando aún más en el uso histórico de la palabra, en el diccionario de los hermanos Grimm descubre Freud un origen común de estos dos círculos de significación: es lo que pertenece a lo familiar y lo que debe quedar oculto ante lo que se considera extraño o extranjero. No en vano Schelling había advertido, según Freud (1966: 236), que "Unheimlich sei alles, was ein Geheimnis, im Verborgenen bleiben sollte und hervorgetreten ist", con lo que nos vamos acercando a la definición que nos interesa y que le interesa a Freud. Algo que tenía que haber permanecido oculto, apunta Schelling, sale a la luz. Incluso, recoge Freud literalmente, en un sentido más primordial "von gespenterhaften freie ort..." (1966: 236). Según se infiere de estas consideraciones, el término entraña una ambivalencia implícita en la que sus significados opuestos han convergido en el lugar en el que lo peligroso y lo oculto se identifican.

Para Jentsch, sigue Freud, el contacto con lo desconocido debe llevar aparejada cierta inseguridad intelectual: "das Unheimliche wäre eigentlich immer etwas, worin man sich sozusagen nicht auskennt. Je besser ein Mensch in der Umwelt orientiert ist, destoweniger leicht wird er von den Dingen oder Vorfällen in ihr den Eindruck der Unheimlichkeit empfangen" (1966: 231). La confianza con la que se mueve uno en su circunstancia varía mucho. Para una persona apenas supone un esfuerzo situarse en un contexto nuevo, como es el caso del intrépido explorador, y para otra, la más leve variación de latitud le afecta sobremanera, como le ocurría al filósofo Immanuel Kant ${ }^{11}$. A Freud este acercamiento le parece acertado pero incompleto. La considera una perspectiva demasiado intelectual. Para corroborar su teoría, intenta verificarla en ejemplos concretos. Tanto Jentsch como Freud analizan al escritor que por antonomasia ha recreado das Unheimliche: E. T. A. Hoffman ${ }^{12}$.

${ }^{11}$ Como es bien sabido, Kant no se alejó nunca de su ciudad natal, Königsberg. "Ordnungssinn und Gewohnheiten waren auch die Ursache, die ihn davon abhielten, Königsberg zu verlassen" SCHULZ (1999: 59).

${ }^{12}$ En el Romanticismo das Unheimliche es un gran Leitmotiv, pues transmuta la cotidianeidad en una perpetua e intensa aventura llena de sorpresas. Hoffmann fue el último y más radical romántico, que no pudo permanecer en lo convencional. Para él la fantasía de la literatura jamás superaría la fantasía de lo real. En cada persona, piensa Hoffmann, se esconden muchas identidades, que funcionan como resistencia frente al encasillamiento burgués de la etiqueta social. Los desdoblamientos esquizofrénicos son muy propios de este autor. A juicio de SAFRANSKI, Hoffmann "erlaubt nämlich die multiple Person" (2010: 445). Otros ejemplos afines al de Hoffmann en este sentido son, con la aparición de dobles, de muertos y otros motivos de inquietud: Der blonde Eckbert (1797) de Ludwig Tieck, Der Schimmelreiter (1888) de Theodor Storm, Reitergeschichte (1899) de Hugo von Hofmannsthal o Die schwarze Spinne (1842) deJeremias Gotthelf. 
En su cuento Der Sandmann (Hoffmann 2004) el fenómeno de das Unheimliche llega a su cenit.

A partir del análisis de este clásico literario, Jentsch perfila más su postura y afirma que das Unheimliche implica "(den) Zweifel an der Beseelung eines anscheinend lebendigen Wesens und umgekehrt" (Freud 1966: 237). Por tanto, la inquietud se produce cuando un objeto inanimado, una muñeca por ejemplo, aparece como animado, movido por una suerte de alma interna (la muñeca Olimpia en la narración de Hoffmann). Y al contrario, procesos que parecen mecánicos proceden de alguien a quien consideramos que tiene alma (por ejemplo, durante el ataque epiléptico de un enfermo, éste parece conducido por procesos puramente mecánicos). Esta inseguridad del concepto, a juicio de Jentsch, crea en nosotros una inseguridad vital, como si no supiéramos a qué atenernos, como cuando a un amigo dejamos de reconocerlo cuando éste habla en sueños. Los procedimientos literarios para provocar esta sensación son variados y con ello nos vamos acercando al nivel de análisis que nos interesa. Para Freud, donde emerge realmente el extrañamiento no es en la anécdota colateral de Olimpia, sino en el motivo central de Sandmann. Este hombre malvado arroja arena en los ojos de los niños que no quieren irse a la cama. Los ojos ensangrentados saltan de la cara y Sandmann se los lleva en un saco para que sus hijitos, con picos como de lechuza, los picoteen. La leyenda es terrible, y al protagonista del cuento lo traumatiza de por vida, temiendo encontrar tras cualquier esquina al causante de dicha pesadilla.

No es necesario asumir las consecuencias analíticas freudianas ${ }^{13}$ para percatarse de que lo esencial se hace patente en la imposibilidad de distinguir el delirio del sentido de la realidad. Tendremos entonces que distinguir entre varios planos de realidad / ficción:

- El lector asume la narración como ficticia, pero también y, a la vez, como un compromiso de realidad dentro de la narración.

- El escritor, por su parte, puede contar hechos como reales o fantásticos y que a su vez el protagonista los viva de verdad o sean producto de su imaginación. Con lo cual los niveles de metaficción se superponen virtualmente.

Pero E. T. A. Hoffmann da un giro al impedir al lector averiguar en qué nivel de realidad se está moviendo, es decir, una vez asumida la perspectiva del protagonista de ficción, es incapaz de averiguar si éste está delirando o no, incluso incapaz de saber si aquél lo sabe. Al asumir esta transgresión de lo sobrenatural en la realidad, se produce das Unheimliche, y lo que se daba por descontado se vuelve problemático. Entonces no es, como afirma Jentsch, que el carácter animado o inanimado de la muñeca se haya difuminado, que más que un temor infantil, parece más bien un deseo primordial de que los juguetes cobren vida; ni, como afirma Freud, que lo macabro del cuento sea la asociación de la ceguera con la castración,

13 "Das Studium der Träume, der Phantasien und Mythen hat uns dann gelehrt, dass die Angst um die Augen [...] ein Ersatz für die Kastrationsangst ist" (FrEUD 1966: 243). 
sino que lo más genuino es la ruptura del sentido de la realidad, que linda escandalosamente con el miedo que puede conducir a la locura ${ }^{14}$. A veces, como en la obra de Kafka, la anormalidad se asume como si fuera normal, creando aún una distancia más penosa para el lector, que ve cómo el protagonista asume como algo corriente lo que a todas luces es una pesadilla descomunal.

Freud pasa a analizar otros motivos desencadenantes de lo inquietante: der Doppelgänger o la presentación de dos personas con idéntica apariencia, cuyo origen el psicólogo rastrea en el infantil narcisismo de la persona y de la sociedad (por ejemplo, los egipcios se dejaban sacar máscaras funerarias para perpetuar el yo más allá de la muerte). Pero hay un sentido más sutil, sobre el que volveremos, que consiste en el desdoblamiento del yo en dos instancias, el yo ejecutivo y el yo reflexivo que ejerce la crítica, para lo que necesita tomar distancias ${ }^{15}$. Este diálogo interno favorece la conversión de la autoconciencia (Bewusstsein) en conciencia moral (Gewissen). Si se produce una ruptura aislante entre ambas instancias se cae en la patología, en la que es imposible crear distancia respecto al yo. Otros motivos de "inquietud", junto al de desdoblamiento, son: regresión al pasado, transferencia telepática de pensamientos y sentimientos o la repetición de un mismo suceso, al que se le atribuye un significado oculto más allá de la casualidad, que Freud emparenta con la compulsión neurótica de repetir rituales, tales como comprobar la cerradura repetidas veces. En realidad todos estos desencadenantes, a juicio de Freud, provienen del ilimitado narcisismo de la infancia, en la que el niño no puede distinguir su yo del mundo objetivo y de los demás ${ }^{16}$. Esta concepción animista del universo, se da tanto a nivel ontogenético como filogenético. Hubo un período inmaduro de la humanidad en que ésta se representaba el mundo como lleno de espíritus ${ }^{17}$. Y de los epígonos de esta cosmovisión no nos hemos zafado. Porque en el fondo creemos en la omnipotencia del pensamiento, "Allmacht der Gedanken" (Freud 1966: 253), en la sobrevaloración de nuestras potencias intelectuales, que fecundan la realidad para asemejarla a nosotros.

${ }^{14}$ Dostoievski en su novela Der Doppelgänger (figura literaria que Freud analizará también en el mismo ensayo) ha presentado magistralmente la imposibilidad para el protagonista (y para el lector) de distinguir qué son elucubraciones suyas y qué es la objetividad compartida. La tensión se mantiene durante toda la novela. Cfr. el estudio de HERRERo (2011).

${ }^{15}$ En su relato Das Dicke Kind, Kaschnitz plantea la ruptura entre la mujer que protagoniza el relato y la niña (a la que termina recordando), entre el yo crítico (presente) y el yo ejecutivo (el que fue en el pasado), imposibilitando de esta manera una asunción de la propia identidad. Al principio la protagonista desconoce esa necesidad de reconciliación que acontece en el relato: ella llega a odiarse de niña, sin saber que es ella misma. $C f r$. el apartado 3 al respecto.

${ }_{17}^{16}$ Cr. la versión más actualizada de esta teoría genéricamente aceptada en PIAGET (2007).

${ }^{17}$ La modernidad supondría un proceso de distanciamiento frente al animismo, hasta el punto de que el mundo se convierte en un objeto de estudio científico y de manipulación tecnológica. Deja de ser el hogar misterioso y mágico donde habita el hombre. Cfr. las notas 2 y 3. 


\section{Los relatos de Kaschnitz como ejemplo de lo "inquietante"}

La selección de los relatos Eines Mittags, Mitte Juni y Das dicke Kind queda justificada porque en ellos muchas de las características que se han señalado aparecen ejemplarmente. Ambos son paradigmáticos en el sentido de que tienen mucho en común con todas las unheimlichen Geschichten de Kaschnitz, sin que por supuesto sea una categoría exhaustiva ${ }^{18}$. Ambos muestran un indisimulado cariz autobiográfico ${ }^{19}$, en ambos acontece un hecho sobrenatural o inexplicable por el que los personajes se acercan a la idea de su propia muerte. Las protagonistas descubren gracias a este hecho algo sobre sí mismas, y el centro neural del recuerdo ocurre en un medio acuático: la lucha por la vida, el esfuerzo por no ahogarse, y el rechazo de la angustia en sentido heideggeriano, tal y como hemos explicado en el apartado 2.1 .

En ambos relatos se dan las características propias de lo unheimlich. Por ejemplo, la figura del Doppelgänger aparece en el primer relato bajo la apariencia de una mujer desconocida, una mujer que la protagonista nunca llega a ver; en el segundo relato, aparece como la niña que la protagonista fue, pero que ella no logra reconocer al principio, y sólo al final de la narración cae en la cuenta de este desdoblamiento. En ambos casos, la conciencia reflexiva se hace cargo de una parte de su pasado, que al 're-descubrirlo', lo integra en el presente. Hay una ganancia de verdad, en el sentido, de que algo que estaba oculto, sale a la luz.

El yo ejecutivo había reprimido estas experiencias: la tentación del suicidio y el 'auto-rechazo' en la niñez con sus complejos y sus tristezas. A su vez, lo que provoca este volver a 'des-cubrir' es un proceso de extrañamiento por el cual, lo que era una realidad normal, queda puesto en entredicho por un suceso anómalo e inquietante.

Lo que pretendo mostrar en suma es que los relatos están vertebrados según el siguiente esquema: un suceso inquietante produce el extrañamiento, y la reflexión en torno a ese suceso lleva al reconocimiento y a la integración de una experiencia que había quedado oculta por la represión o por una vida debilitada.

\subsection{Análisis del relato Eines Mittags, Mitte Juni}

Eines Mittags, Mitte Juni es un relato que M. L. Kaschnitz publicó en 1960, dos años después de la muerte de su marido. Es un período en el que la búsqueda del yo se intensifica, y prácticamente todas las inquisiciones se encaminan hacia

18 También se centra esta escritora, sin emplear tal recurso, en la incomunicación en la pareja (Der Spaziergang 1927-31), en la niñez (Nesemann 1952) en el nazismo (Ein Tambourin, ein Pferd 1966), en la adolescencia (Lange Schatten 1960), etc.

19 En el primero la protagonista se llama Kaschnitz, su hija (como en la vida real) Constanza. Ambas estuvieron en Italia y un guiño irónico del destino: Kaschnitz acabaría muriendo realmente en Italia, como se anuncia en el relato sobre la protagonista. Su vida real acabó haciéndole un guiño a la ficción. En el segundo, la protagonista describe un episodio de su infancia en Potsdam, a su hermana Lonja, su afición por el patinaje, etc. Ella misma lo ha admitido en numerosos lugares: "Ja, das dicke Kind bin ich selbst” (BIENEK 1965: 286). 
tal fin ${ }^{20}$. Este relato aparece en Lange Schatten. Erzählungen, en la editorial Claassen de Hamburgo y es el segundo libro de relatos que publica. Aún aparecerán dos más. Y dentro de este género crecerá su prestigio como autora. Setenta relatos llegó a publicar en vida, aparte de todos los que quedaron sin ver la luz, que superan la veintena, algunos de muchísima calidad ${ }^{21}$.

La acción del relato se centra en el regreso de una mujer tras unas vacaciones que ha pasado con su hija en Italia. Cuando dicha mujer se dispone, ya de vuelta, a recoger las llaves de su vivienda en casa de una vecina, ésta le da una noticia sorprendente: alguien, una desconocida, vino un día mientras ella estaba de vacaciones, e informó sobre su muerte. La protagonista, al principio ligeramente molesta, endereza, según avanza el relato, todos sus esfuerzos en investigar obsesivamente quién ha dicho eso y por qué, lo que supondrá paralelamente un viaje hacia sí misma. Se informa y descubre que la desconocida que había hablado en el vecindario sobre su muerte y que además quería quedarse con su propia vivienda, vino cierto mediodía a mediados de junio. Guiada por presentimientos, la protagonista consulta su diario para averiguar qué estuvo haciendo ella exactamente ese día a esa hora.

Lo que desencadena la atmósfera inquietante sin embargo no es tanto la noticia de la propia muerte, que por sí misma justificaría la pertinencia de la categoría interpretativa, pues la portadora de la macabra noticia es calificada por Kaschnitz como una "unheimliche Person" (1982: vol. 4, 290) y que podría haber sido obra de una persona alterada, sino su efecto sobre la protagonista, que queda muy turbada. Se ha introducido un elemento que ha quebrado la naturalidad aceptada de lo cotidiano. El lector sabe que la noticia de la muerte no es pueril ni anecdótica, sino que se suma a la protagonista en sus pesquisas, creando con ella un estrecho círculo de complicidad, para aclarar el papel que desempeña esa noticia, a todas luces falsa. Gracias a este camino de extrañamiento, volverá sobre sí misma para alumbrar facetas oscurecidas y olvidadas de su personalidad.

Ese día, a mediados de junio, la protagonista está de vacaciones de verano junto a su hija Constanza en la costa italiana. El sol es radiante, el agua calma. Puede recordar cada detalle: "Auf dem weissen Sand unter dem Sonnenschirm meine schwarzen Kleider, schwarze Strümpfe, schwarze Schuhe" (1982: vol. 4, 292). En el recorrido de sus propios recuerdos la autora necesita repasar cada matiz, pormenorizar, recuperar la mirada atenta, como si tuviera que reintegrar la experiencia completa del pasado en el presente consciente. Como señala Whissen (en Kaschnitz 1995: 15), la escritura para Kaschnitz suponía una especie de terapia libertadora. En ese sentido, tenía que aprender a ver cada cosa de nuevo, presentarla en su singularidad, en una especie de discurso fluido desde el inconsciente. Inmersa

${ }^{20}$ En realidad su literatura ha sido una eterna búsqueda de una identidad dañada. Los trabajos académicos más recientes se centran de hecho principalmente en este aspecto, de lo cual son muestra los de Huber-SAuter (2003) y VetTer (1994).

${ }^{21}$ Der Spaziergang en KASCHNITZ (1982: vol. 4, 782-787) o Rätsel Mensch (1982: vol. 4, 869879). 
en este paisaje veraniego, la protagonista decide nadar mar adentro, lejos, tan lejos, que apenas puede percibir figuras en la orilla. Se envuelve en la soledad de la distancia, hasta donde no llega el ruidoso ajetreo de las playas del sur. Flotando sobre el agua, "haciendo el muerto", según aparece en el texto: "dann denke ich nichts mehr, schwimme weiter, halte die Augen unter Wasser offen, sehe tief" (1982: vol. 4, 292). El lector sabe que la muerte merodea, porque la noticia previa de su fallecimiento ha cubierto de un halo de premonición todo el argumento. Y ella se pregunta de pronto por qué volver a la orilla, "warum eigentlich, es ist doch alles verloren, du hast dich nicht halten lassen" (1982: vol. 4, 292). Nada más nos dice la protagonista. No asocia ningún recuerdo fatídico a la perezosa sensación de desprendimiento que tiene. Nada en especial conduce su pensamiento. Simplemente no encuentra un motivo para seguir con su existencia. El "todo está perdido" no se refiere tanto a la suma de las cosas que ha tenido, como indicaba Heidegger, sino al mundo en su sustantividad, tal como leímos en las propias palabras del filósofo: "die Welt vermag nichts mehr zu bieten, ebensowenig das Mitdasein Anderer" (1977: 249). La protagonista se desconecta del mundo y se desprende del cordón umbilical por el que entra el alimento y el orden del mundo: "oben und unten sind dasselbe, oben und unten sind die seligen Geister" (1982: vol. 4, 293). El relato pierde aquí su exposición tradicional para convertirse en una digresión de pensamientos que desfilan por la mente de la protagonista ${ }^{22}$ mientras se ahoga lentamente. En este punto, la perspectiva de lo unheimlich ha pasado de un nivel psicológico (Freud) a uno existencial u ontológico (Heidegger).

La protagonista se ha desconectado del mundo: el alejamiento espacial (mar adentro) ha conllevado un alejamiento emocional (al menos de su hija, que la espera en la orilla). La muerte se presenta como una tentación inocentemente disfrazada. Kaschnitz recurre a la imagen de Circe, halagadora, intentando retener con agasajos a Ulises. Sería tan fácil dejarse llevar. Ítaca supone para Ulises el horizonte de la muerte y sin embargo desea regresar y abandonar las promesas de Circe. Kaschnitz, por el contrario, se permite un momento de duda, no sabe si abandonarse y morir o regresar y vivir, en movimiento inverso a Ulises. En este momento de radical ruptura (Kreutzwald 2007: 190) emergen las imágenes primordiales, los arquetipos del inconsciente colectivo que moldean la tradición cultural occidental. Por eso en este punto crucial Kaschnitz se sirve de la mitología griega y de sus poderosas imágenes. Y sin embargo, al romper el círculo de soledad se abre de nuevo a la vida. Kaschnitz establece un paralelismo entre la soledad y la muerte. Literalmente ella encuentra la salida del laberinto heideggeriano gracias a su hija.

Como hemos anotado al principio de este epígrafe, Kaschnitz había enviudado recientemente - las ropas negras bajo la sombrilla- al concebir este relato. Estaba profundamente enamorada de su marido y se siente muy sola. Encuentra un resorte

${ }^{22}$ La denomino como "protagonista", porque en la ficción posee el mismo nombre que la autora (Kaschnitz), y es preferible no introducir confusiones en los niveles del discurso. 
de vitalidad en su única hija, que en el relato la está saludando desde la orilla, desde la vida.

En los relatos de Kaschnitz se conjuga la profundidad del análisis psicológico con la delectación en la descripción poética. Sin embargo, una de sus características más sobresalientes es el fondo de abismo, casi de angustia, que late bajo los conflictos de sus protagonistas. Para merodear esa zona opaca se sirve de medios tales como lo extraordinario (una falsa muerte anunciada por un personaje inquietante), la ruptura del sentido de la normalidad (la vida pierde su sentido mar adentro), o la transformación del personaje (renueva sus ganas de vivir). La estructura general del relato ha sido descrita por Joan Curl Elliot (1973: 2 y ss.) como un proceso de 'des-cubrimiento', es decir, un poner al descubierto, que conduce a un cambio de perspectiva. En este sentido, el traer a la luz de la conciencia, bewusstmachen, corre paralelo a la función terapéutica del psicoanálisis. La alusión romántica a lo abisal, la inquisición de las zonas más oscuras de nuestra vida interpretada, deviene en una reivindicación de aquella zona de nuestra personalidad irreductible a un análisis racional, según ella aclara: "meine Figuren [...] stehen alle unter der Einwirkung rationalistisch nicht zu erklärender Mächte, gegen die sie ankämpfen oder denen sie sich beugen oder an denen sie zugrunde gehen" (1982: vol. 7, 751). El equilibrio mental no es restablecido hasta que no se asumen las experiencias reprimidas, desterradas de la memoria.

Kaschnitz traza una conexión mágica entre dos hechos objetivos y aparentemente inconexos: un día determinado la protagonista está a punto de morir ahogada y al mismo tiempo y en otro lugar una desconocida anuncia su muerte. Este último hecho permanece inexplicado. Aunque el lector queda lejos de pensar que es una mera coincidencia. ¿Cuál es la realidad de esa figura, de la desconocida? ¿Un Doppelgänger? ¿Acaso la figura de la muerte? Pero los vecinos la han visto, la han oído hablar. No pueden ser delirios de la protagonista y al parecer tampoco de la narradora. Este procedimiento es muy usual en las narraciones de Kaschnitz, y hace que el propio lector se una a su perplejidad, como si nadie pudiera desentrañar el misterio ${ }^{23}$.

Narrativamente Kaschnitz da un giro final, por el que se establece "objetivamente" la relación entre aquellos dos hechos, uno real y el otro mágico. A punto de ahogarse, y ya rendida al canto de sirenas del instinto de Thanatos, según Freud definía la tendencia que existe en el sujeto hacia la propia destrucción, la protagonista escucha de pronto un sonido de flauta. Su hija de hecho toca la flauta y esta asociación y el acto de pensar en su hija la arrastra de nuevo hacia el lado de la vida. Ante el cuestionamiento de in-der-Welt-sein, definido como la angustia radi-

${ }^{23}$ En Jennifers Träume (1969) la hija de la protagonista sueña con una familia que en realidad existe; en Gespenster (1960) se produce un encuentro de un matrimonio con unos jóvenes que hacía tiempo, según se enteran después, habían fallecido; en Der Thunsch (1966) una figura irreal y legendaria comete un asesinato que nadie sabe resolver; en Eisbären (1966) el marido, recién fallecido en un accidente, hace desde el más allá una última visita a su esposa. Esto es sólo por poner algunos ejemplos en los que se sigue el mismo modelo de binomio ficción/realidad. 
cal y ontológica, según aparece en Heidegger, las raíces vitales, de sangre de la protagonista, le hacen superar esa soledad y el Mitdasein-Anderer heideggeriano sí compensa. La unión de ambas situaciones, es decir, la de la visita de la desconocida y la de la tentación de suicidio, se produce cuando la protagonista averigua la razón de que la desconocida acabara marchándose; porque alguien, le cuenta la vecina, introdujo en la conversación el tema de la hija. Entonces no estaba sola. Esa es la clave. De esta forma tan mágica ha sabido Kaschnitz superar la Unheimlichkeit heideggeriana.

\subsection{Análisis del relato Das dicke Kind}

Es este un relato de suma importancia, no solo por la introspección narrativa y la agudeza psicológica que presenta, sino también por la belleza del lenguaje utilizado, a veces poético, a veces de una dureza casi kafkiana ${ }^{24}$. Es sin duda uno de los más conocidos y el favorito de la autora ${ }^{25}$. Publicado en 1952, colocó a su autora de repente dentro de la esfera pública. El contenido de la acción no es muy extenso: la protagonista del relato tiene la costumbre de prestar libros a los niños de la vecindad (Kaschnitz trabajó de librera mucho tiempo). Sin duda la guerra no había dejado muchas bibliotecas en pie. Un día se presenta en su casa una niña de aspecto interesante y repulsivo a un tiempo, desconocida y sin embargo de alguna forma reconocida, que no está interesada en los libros. Su aparición es repentina y extraña, "weil es leise hereingekommen war, hatte es mich erschreckt" (1982: vol. $4,58)$. La relación entre la niña y la mujer evoluciona desde una objetividad distante (las preguntas a la niña son banales, como si no quisiera tener que ver mucho con ella) hasta una subjetividad contrariada. Los sentimientos de repulsión y angustia se van acentuando paulatinamente en la narración hasta el punto de contagiar al lector. Esta tensión alcanza su clímax en el final, cuando ambas figuras quedan identificadas: "blickte in das weisse Antlitz unter mir, und wie ein Spiegelbild sah es mir entgegen" (1982: vol. 4, 65). La niña aparece como una figura unheimlich en el sentido de Schelling (cfr. el apartado 2.2.), algo que tenía que permanecer oculto ha salido a la luz. Y la razón de esta epifanía es la exposición de una transformación. A juicio de Trepte (2004: 81), todo el relato es un arsenal simbólico predispuesto para el momento de esta Verwandlung.

Tras un rato de incómoda comunicación, la niña abandona la casa, y la protagonista la persigue por lugares que parecen pertenecer al pasado o que en cualquier caso le son extraños. Hay una contraposición de lugares y tiempos: la casa es el presente, donde la protagonista se siente segura y la niña inquieta y observada. El lago, hasta donde la niña llega, es el pasado, la niña allí se siente en libertad, pero la protagonista se siente perturbada. Un cambio en el aire ha anunciado el deshielo. La niña comienza torpemente a patinar sobre el lago helado y el hielo se

\footnotetext{
24 “Ich hatte die Geschichte 'Das dicke Kind' für meine stärkste Erzählung, weil sie am kühnsten und am grausamsten ist. So grausam zu sein konnte mir nur gelingen, weil das Objekt dieser Grausamkeit ich selber war" (1982: vol. 7, 751).

${ }^{25}$ Traducción de Martín Arnedo (KASCHNITZ 2013).
} 
resquebraja fatalmente bajo sus pies. Está a punto de ahogarse en el agua, y de pronto transforma (la Verwandlung) su apatía en determinación para eludir el peligro. Tras observar todo esto desde cierta distancia, la protagonista vuelve a su casa y encuentra sobre su escritorio una foto de su infancia, con la apariencia exacta de la niña, abriendo la posibilidad de que todo haya sido un recuerdo. Y lo normal, lo heimlich, se restablece circularmente al volver a casa.

¿Es la niña alguien real? Existen razones para pensar en una respuesta afirmativa y en una negativa. Por un lado, las vivencias que describe la protagonista no parecen de su invención: cómo persigue a la niña, cómo la observa al comer, etc. Todas las acciones están presentadas como objetivas. Por otro lado, cuando describe a una vecina el lago en el que ha estado con la niña, la respuesta de aquélla es contundente: "das gäbe es nicht" (1982: vol. 4, 65). Con lo que se produce una ruptura inquietante con la realidad compartida ${ }^{26}$. Podría tratarse entonces de alguien que recuerda su infancia, su triste infancia. Por consiguiente, el final sería una introducción: revolviendo entre sus papeles encuentra una foto de su infancia, foto que activaría el recuerdo. Ambas tesis son sostenibles y en realidad la irresolución de esta pregunta es más potente que una respuesta unívoca: hace pensar más al lector.

Otra ambigüedad muy solvente narrativamente es la descripción connotativa de la niña: la repulsión que produce en la protagonista ¿es como ella se veía de pequeña?; ¿como la veían los demás?; ¿como se recuerda ella de mayor? En cualquier caso hay un intento de ajustar las cuentas con el pasado ${ }^{27}$. La niña, cuyo nombre jamás se desvela, llamada simplemente "la gorda", tiene doce años, edad propicia para buscar la amistad, la aventura, la aceptación. Pero su aspecto la convierte en objeto de complejos. En la escuela -según ella cuenta- está aislada, no parece tener "una mejor amiga". La esclavitud hacia un prototipo de éxito social y la importancia de la imagen están jugando un importante papel de fondo, que marca la adolescencia.

Ciertos conflictos no resueltos ${ }^{28}$ de su infancia propician la entrada de lo sobrenatural (Freud). Lo que se piensa real, en el último giro del relato (la foto encon-

${ }^{26}$ En el sentido de Jentsch -apartado 2.2.- lo unheimlich surge desde el momento en que el lector no puede distinguir si la niña es un recuerdo u otra persona real.

${ }^{27}$ El relato describe una doble metamorfosis: la apatía de la niña se transforma en determinación cuando lucha por su vida en el hielo, y por otro lado el rechazo de la protagonista hacia su infancia se convierte en aceptación cuando logra, por así decirlo, verse desde fuera. Metafóricamente funciona muy bien la comparación de la niña con un gusano, tal y como aparece en el relato, pues éste acaba convirtiéndose en mariposa tras deshacerse de la crisálida.

${ }^{28}$ Por ejemplo, el conflicto con su hermana. Kaschnitz presenta en el relato la relación de la niña con su hermana (es decir, con Lonja) de forma muy asimétrica. La hermana es delgada, deportiva, atrevida: "Sie hat niemals Angst" (1982: vol. 4, 62), incluso creativa: "Sie macht Gedichte" (1982: vol. 4, 62). Ella por el contrario es gorda -según reza el título-, lenta (como un gusano) y siempre tiene miedo. La niña abandona la casa de la protagonista para reunirse con su hermana. Mientras ella se atasca en el hielo, su hermana patina con la ligereza de una bailarina. Los sentimientos de la hermana no se describen nunca, pero la protagonista/niña confiesa su admiración por ella: cuando se 
trada) pone en cuestión el grado de ficción. Este giro es paralelo al del relato anterior. No obstante, en este relato, das Unheimliche está más cerca de Freud que de Heidegger, pues el origen del malestar proviene de determinado rechazo a cierta idea de sí misma, pero no de una angustia sin objeto. Kaschnitz utiliza de nuevo la imagen del Doppelgänger -mujer/niña- como forma de autodescubrimiento. Y los medios formales están inmejorablemente traídos en función de este objetivo. La lengua es sencilla y presenta sin efectismos la realidad bruta. Como señala Trepte (2004: 77), su lenguaje "rückt das Leben ins Zwielicht: in ein Niemandsland zwischen Hell und Dunkel, zwischen Tag und Traum; das Irrationale und Surreale drängt an die Öberflache [...] lässt oft nur eine leise Verstörung zurück".

La naturaleza se presenta intencionadamente antropomorfizada: cuando el hielo se rompe, parece bramar desde la profundidad un lamento: "denn nun begann mit einemmal dieses seltsame Stöhnen, diese tiefe Seufzer, die der See auszustoßen scheint, ehe die Eisdecke bricht. Diese Seufzer liefen in der Tiefe hin wie eine schaurige Klage" (1982: vol. 4, 64). Y en general la utilización de adjetivos como "negro" o "acuoso" predispone al lector para el desenlace del conato de ahogamiento. El mismo cambio de tiempo, el deshielo, parece una metáfora de la ruptura del capullo, de la crisálida, del 're-nacimiento' de la niña. En numerosos lugares es descrita como una niña de agua. El adjetivo wässerig se utiliza negativamente en la descripción de la niña, como alguien que se mueve sin puntos fijos, sin una definición o consistencia propia, y al mismo tiempo sin destreza, "es brachte mir alles wässerig Dumpfe, alles Schwere und Trübe der Menschennatur" (1982: vol. 4,61 ). Cuando la protagonista pregunta a la niña (que posee por otra parte "wasserhellen Augen") cuándo ha nacido, ella responde: "Im Wassermann" (1982: vol. $4,59)$. Curiosamente responde con su horóscopo, un elemento más del imaginario mágico y que además comparte con Kaschnitz, que también es acuario. Haber nacido en un signo de agua puede relacionarse también con la ruptura del hielo al final del cuento. En la narración el agua es símbolo de peligro y de 'renacimiento', de volver a nacer. La densidad simbólica va predisponiendo al lector, sin que éste se dé cuenta, en un registro emocional que Kaschnitz va manipulando. Cuando la niña está en peligro en el lago helado, la protagonista no siente "das geringste Erbarmen" (1982: vol. 4, 64), porque sabe que no necesita su ayuda. La niña lo ha comprendido y ha nacido, desde el agua, de nuevo. Ha mantenido "ein schreckliches Ringen um Befreiung und Verwandlung, wie das Aufbrechen einer Schale oder eines Gespinstes" (1982: vol. 4, 65) y ha triunfado. Quien triunfa en realidad es la adulta que la observa sin intervenir.

Y sin embargo, no es un final consolador. En lo profundo de la situación planteada por Kaschnitz, late una exposición de las condiciones existenciales básicas

acerca al lago a ver a la niña gorda patinar, descubre que en realidad lo que buscaba era ver a su hermana mayor, a la que llama "das Kind nach meinem Herzen” (1982: vol. 4, 63). 
de la persona (Heidegger). Los personajes se enfrentan radicalmente con esta opacidad. Öbstbö (1997: 69) no puede expresarlo mejor:

Fast ohne Ausnahme werden [...] die Erzählfiguren mit den Bedingungen ihres Daseins konfrontiert, mit der Lebenswirklichkeit als Herausforderung zur ichRealisierung, mit ihren Mitmenschen als Mahnung zur Sozialisation, mit der Liebe als Antrieb zur ich-Ausweitung, mit dem Tod als Zwang zur Selbsterkenntnis, mit der Natur als gleichsam aufbauender und zerstörischer Kraft, mit dem Irrationalen als übermenschlicher und innermenschlicher Dimension.

Kaschnitz señala el punto ciego por el que el círculo de la (auto)comprensión nunca se cierra del todo.

\section{Conclusiones}

Podemos afirmar que en muchos de los relatos de Kaschnitz se repite una estructura narrativa común, que consiste en la transformación de los protagonistas y de la percepción que tienen de ellos mismos. Dicha transformación es provocada por una circunstancia que a ellos $-\mathrm{y}$ al lector- se presenta como unheimlich e inexplicable. En los dos relatos que hemos analizado esta circunstancia ha sido, por un lado, el encuentro de la protagonista con la niña que fue, y, por otro, la noticia de su propia muerte. Gracias al extrañamiento que dicha situación provoca, gracias a esta ruptura con la normalidad, los personajes pueden acceder a un autoconocimiento que de pronto se ha vuelto explícito. Por una parte, el fondo ontológico de angustia que late en su interior se puede examinar a partir de los análisis que Heidegger realizó sobre lo "inquietante" en Sein und Zeit. Por otra parte, los mecanismos psicológicos que operan en dichos personajes salen a la luz gracias a la propuesta psicoanalítica de Freud. Para Heidegger, la angustia ontológica no tiene un origen concreto en el mundo. Freud, por el contrario, piensa que la angustia psicológica conlleva de forma oculta un proceso de represión. $\mathrm{Y}$ ambos filos de la angustia fluctúan alternativamente en los relatos de Kaschnitz, en el sentido de que la autora tematiza el descontento atribuyéndole a veces un motivo concreto y otras veces no. Que la protagonista de Eines Mittags, Mitte Juni sienta la tentación del suicidio, no es atribuible a ninguna experiencia traumática, con lo que cabe suponer con Heidegger que el hastío existencial proviene de una debilitación de los impulsos vitales, que no encuentran un sentido último para seguir con el juego de la vida. Sin embargo, la protagonista de Das dicke Kind conoce perfectamente el origen de su angustia: es esa niña gorda, torpe y solitaria, que envidia a su hermana por tener lo que ella ansía. Y no la acepta. No acepta su propia niñez, porque no ha superado los complejos infantiles que la atormentaban entonces. Y consideramos que esta doble raíz de la angustia (que es puesta en marcha narrativamente por lo unheimlich), es un esquema que funciona bien como método de análisis para categorizar las reacciones de las protagonistas en los relatos de Kaschnitz. 
Creemos que el doble planteamiento surge de la propia concepción de la autora. A veces aparece simplemente como una visión metafísica de la vida en su conjunto y otras veces posee un perfil psicológico muy definido. Ella misma admite que no tenía razones objetivas para sentirse tan desgraciada en su infancia. Pero en Das dicke Kind enumera varias. Por eso, esta ambigüedad se reproduce en su obra. Y obra y vida están en Kaschnitz íntimamente imbricadas.

Lo "inquietante" como categoría hermenéutica puede ser esclarecedor, siempre y cuando no olvidemos, tal y como hemos apuntado anteriormente, que la tarea de interpretar, de comprender, nunca se cierra sobre sí misma, nunca convierte en transparente lo que por sí mismo no lo es. Y no lo es respecto al texto, ni respecto a la comprensión de la propia existencia. Y ambos aspectos se entretejen obsesivamente en la escritura de Kaschnitz.

\section{Referencias bibliográficas}

APel, K., Transformation der Philosophie. Band 2. Das Apriori der Kommunikationsgesellschaft. Frankfurt am Main: Suhrkamp 1976.

BIENEK, H., Werkstattgespräche mit Schrifstellern. Múnich: dtv 1965.

DODERER, K., Die Kurzgeschichte in Deutschland. Ihre Form und ihre Entwicklung. Darmstadt: Wissenschaftliche Buchgesellschaft 1977.

DudEN, Das Herkunftswörterbuch. Mannheim: Bibliographisches Institut \& Brockhaus AG 2012.

Elliot, J. C., Character Transformation through Point of View in selected Short Stories of Marie Luise Kaschnitz. Tennessee: Nashville 1973.

FREUD, S., Gesammelte Werke. Frankfurt am Main: S. Fischer 1966, 229-268.

HABERMAS, J., Theorie des Kommunikativen Handelns. Bd. I Handlungsrationalität und gesellschaftliche Rationalisierung. Frankfurt am Main: Suhrkamp 1981.

HeIDEGGER, M., Sein und Zeit. Frankfurt am Main: Vittorio Klostermann Gesamtausgabe 1977.

HeRrero CeCILIA, J., «Figuras y significaciones del mito del doble en la literatura: teorías explicativas», Cédille. Revista de estudios franceses, Monografías 2 (2011), 15-48.

HofFMAnN, E.T.A., Der Sandmann. Stuttgart: Rudolf Drux 2004.

HUBer-SAUter, P., Das Ich in der autobiographischen Prosa von Marie Luise Kaschnitz. [Dissertation]. Stuttgart: Universität Sttutgart 2003.

JENTSCH, E., «Zur Psychologie des Unheimlichen», Psychiatrisch-Neurologische Wochenschrift 8.22 (1906), 195-198.

KASCHNITZ, M. L., Lange Schatten. Erzählungen. Hamburgo: Claasen 1960.

KASCHNITZ, M. L., Vogel Rock. Unhemliche Geschichten. Frankfurt am Main: Suhrkamp 1969.

KASCHNITZ, M. L., Gesammelte Werke. Frankfurt am Main: Insel 1982.

Kaschnitz, M. L., Long Shadows. Trad. y ed. de A. Whissen. Columbia: Candem House 1995.

Kaschnitz, M. L., Das dicke Kind und andere Erzählungen. Text und Kommentar. Ed. de A. BACHMANN / U. SCHWEIKERT. Frankfurt am Main: Suhrkamp 2002.

KASCHNITZ, M. L., «La niña gorda». [Trad. de S. Martín Arnedo]. Hermeneus Revista de Traducción e Interpretación (TI) 15 (2013), 409-415. 
KReutzwald, A., Das unsagbare zum Ausdruck bringen: Die Sprache der mythologischen Bilder. Motive und Figuten in Werk von Marie Luise Kaschnitz. Trier: WVT. Wiss. Verlag 2007.

MATT, P. von., Literaturwissenschaft und Psychoanalyse. Stuttgart: Reclam 2001.

MIKYUNG, K., Entfremdung als Problematik in den autobiographischen Prosawerken bei Marie Luise Kaschntiz. Frankfurt am Main: Lang 2003.

ÖвSтвӧ, J., Wirklichkeit als Herausforderungs des Wortes. Engagement, poetologische Reflexion und dichterische Kommunikation bei Marie Luise Kaschntiz. Freiburg: Rombach 1997.

Oldenhage, T., Parables of our Time, Rereading New Testament Scholarship after the Holocaust. Oxford: Oxford University Press 2002.

Piaget, J., La representación del mundo en el niño. Madrid: Morata 2007.

PouH, L., Wiener Literatur und Psychoanalyse. Frankfurt am Main: Felix Dörmann, Jakob Julius David und Felix Salten 1997.

RATTNER, J. / DANTZER, G., Literatur und Psychoanalyse. Würzburg: Königshausen \& Neumann 2010.

SAFRANSKI, R., E.T.A. Hoffmann: Das Leben eines skeptischen Phantasten. Frankfurt am Main: S. Fischer Verlag 2010.

SCHULZ, U., Kant. Hamburgo: Rowohlt 1999.

TOWARNICKI, F., «Entretien avec Heidegger», L'Express, n 954, $20-26$ octubre (1969), 20-26.

TREPTE, K., 2 Leserinnen lesen. Studien über Identification bei der Literaturrezeption. [Diplomarbeit]. Freiburg: Universität Freiburg im Breisgau 2004.

VetTer, H., Ichsuche. Die Tagebuchprosa von Marie Luise Kaschnitz. [Dissertation]. Hannover: Universität Hannover 1994.

WitTGEnsteIn, L., Tractatus Logico-Philosophicus. Madrid: Alianza 1973.

Weber, M., Gesammelte Aufsätze zur Wissenschalftslehre. Tübingen: Johannes Winckelmann 1985. 